\title{
Hacia la construcción ética del hombre desde una perspectiva filosófica
}

\author{
Licdo. José Miguel Amaya
}

L as caregorías básicas que permiten la elaboración de un pensamiento ético son la libertad y la responsabilidad. La capacidad del hombre de autodererminarse, de asumir la dirección de su vida, y de ejercer esta capacidad en una acción concreta, lo determina como hombre libre y en cuanto libre, un sujeto érico. La posibilidad de la autodeterminación introduce lo ético en lo que se refiere al hombre. Para que haya una acción moral, es necesario que junro a la acción voluntaria (libertad de voluntad) haya una elección (libertad de elección o libre albedrío). La libertad por lo tanto, no es una acción física sino una cuestión moral (es incrínseca a la acción moral) y en el ámbito de la moral no solo hay libertad, sino que, no puede no haberla.

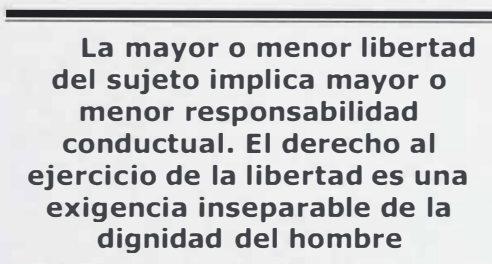

La libertad moral es la posibilidad de ejercer una acción moral. No consiste solo en la posibilidad de elegir, sino que en la medida de esa elección, que contribuya al crecimiento verdadero de la persona. Esa elección no solo se refiere al enfrentamiento de posibilidades elegibles, sino además, significa una elección sobre sí misma a favor o en contra del bien o de la verdad. Por lo tanto, el referente de la libertad humana no es la ley sino la verdad, ya que sólo por medio de ésta, se encuentra la misma libertad. La verdad orienta la libertad, la encamina a su plenitud y permite la convivencia humana. Libertad es la faculrad de disponer de si mismo; de obrar (o no obrar) por sí mismo acciones deliberadas. Estas alcanzan su perfección cuando se realizan en virtud del bien supremo. Caracteriza los actos propiamente humanos, actos voluntarios y responsables del autor, es decir, hace al ser humano responsable de los actos de que es actor voluntario (es propio del hombre actuar deliberadamente).

La responsabilidad significa la ejecución reflexiva de los actos, ponderando las consecuencias del bien y mal en cuanto a alcanzar cuotas mayores de humanización, crecimiento individual y social. En el campocristiano se estima la ausencia de principios seguros, que garanticen las relaciones justas entre los hombres, de no ser por la existencia de una verdad trascendente, por medio de la cual, el hombre conquista su plena libertad. De no reconocer esta verdad trascendente, triunfa la fuerza del "poder interesado" que no respeta el derecho de los demás. Hasta que el hombre no llegue a encontrarse definitivamente con su último bien que es Dios, la libertad implica la posibilidad de elegir entre el bien y el mal, $y$. de por lo tanto crecer en perfección, o de flaquear $y$ de pecar. La libertad hace al hombre responsable de sus actos en la medida que éstos son voluntarios. El progreso de la virtud y el conocimiento del bien hacen crecer el dominio de la voluntad. Libertad humana significa responsabilidad del sujeto (que a su vez supone libertad). La mayor o menor libertad del sujero implica mayor o menor responsabilidad conductual. El derecho al ejercicio de la liberrad es una exigencia inseparable de la dignidad del hombre. En la medida que la persona hace más el bien, se va también haciendo más libre.

\section{Antropologia de los valores}

T a libertad hace comprender al hombre como proyecto, Lya que conjuga la responsabilidad frente a la realización y crecimiento de la humanidad. La Antropología es el factor clave para la reflexión ya que constituye un horizonte ético, siendo la realización de la persona en sociedad su preocupación central. Es la base por la cual elabora su reflexión. Entrega orientaciones en cuanto a la responsabilidad de crecimiento tanto en lo personal (mayor dignificación) como en lo social (mayor humanización). En cuanto a la ética, la persona es básicamente un "ser para el 


\section{Hacia la construcción ética del hombre desde una perspectiva filosófica}

Universidad Tecnologica de El Salvador

encuentro". En éste, lapersona se descubre como sujetofrente a si mismo ("yo") y alteridad frente a otros ("tu"), dentro de un contexto social ("nosotros"). Hil crecimiento de la persona gira en torno a la subjetividad (formación de una personalidad que repercute directamente en la relación con los demis); la reciprocid.ad (relación constante con los demis) y lia responsabilidad social (hacerse parte de los demis).

El hombre es un ser social. Conmura relaciones que le permiten determinar su identidad. Su capacidad de alreridad se manifiesta por ser esencialmente indigente; tener sentido de pertenencia (formar parte) y de apertura al encuentro con otros. La responsabilidad colectiva es positiva en la medida de la existencia de la solidaridad para superar el mal. En cuanto a su afectividad, denora tener sentimientos que llevados a la prácrica supone sentido de responsabilidad y por lo tanto de consideración érica. El sentimiento más fundamenral es el amor que el mismo bien despierta; amar es el desear el bien a alguien. Se dice que los sentimientos son moralmence buenos cuando contribuyen a una acción buena.

\section{Racionalidád ética}

T a ética es una consecuencia de la razón, ya que denero ¿de la racionalidad buscal descubrir el significado auténtico de la realidad humana. Sólo la razón da válida cabida al discurso ético. De la acción humana, se constatan sentidos que se convierten en fines conseguidos por previa aceptación de preferencias. Las preferencias éticas son elegidas racionalmente con imparcialidad y bajo estricta "pureza original". Sólo asi se puede configurar la justicia como imparcialidad racional, criterio pormedio del cual se orienta éticamente la historia humana. Además, la racionalidad ética se concreta en el principio de responsabilidad. De lo anterior se deduce que la ética se mueve denero de la racionalidad critica (organizada mediante el dialogo entre las personas), orientada a descubrir el auténtico significado de la realidad humana. La ética dialógica puede ser la base para construir y vivir la racionalidad érica en el momento presente.

\section{¿Tiene la ética fundamento filosófico?}

E n la érica se compromere el destino del hombre en su llamado a ser, cuál es su fin y qué sentido tiene su existencia. Sin embargo, efecrivamente tiene una razón de ser, que la vida sí riene un sentido. Sin que nadie la programe o dirija se orienta hacia sus propios fines. El hombre proyecta su vida con los talentos que le han sido dados, pero que como todo proyecto riene un fin. La érica ha ocupado un lugar en la filosofía desde el surgimiento mismo de la filosofía. La responsabilidad érica en filosofía ha sido llevada a la sabiduría. Si la moral fuera to que a uno mismo le complace, confirmando o validando los actos, entonces se adecuaría la moral a medida, convirtiendo la medida moral en nuestros propios intereses y no en el proyecto de un destino. La

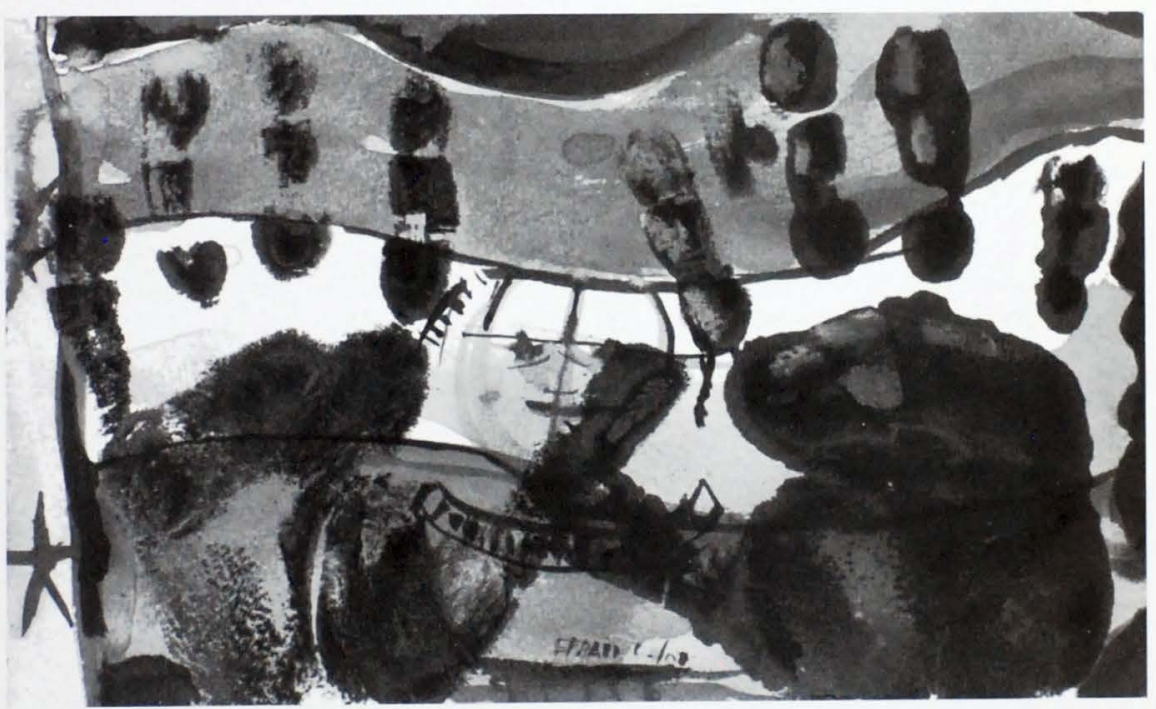


filosof ła definió por "felicidad" el proyecto de la vida propio del destino humano. Esta felicidad es iluminada por la idea platónica del bien. Pero la moral no es necesariamence una doctrina filosófica. Un ejemplo de ellos son los mandamientos, que siendo el mayor imperativo moral, no riene su origen en la filosofía.

La moral puede ser y no ser una disciplina filosófica. La vida humana conlleva de una manera espontánea un orden ético, que es a su vez la fuerza por la cual el hombre crece. Este orden ético proviene primeramente del núcleo familiar (educación). En ella reside el primer aliento moral y sólo luego, saldrá a la conquista de su destino. El primer ámbito ético es la familia. La filosofía moral viene después. Ella esta llamada a establecer el principio fundamental desde donde se edificará tanto el carácter como la costumbre. El principio fundamental ético se basa en tres pilares: la Libertad; la Virtud y el Bien, por los que la filosofía moral se encuentra asentada. No hay cuestión ética sino en el ámbito de la libertad. En ella el hombre está entregado a su propio ser (quehacer). La virtud es la capacidad permanente de hacer bien hecho el trabajo de la libertad. En la libertad la acción virtuosa se prolonga. La libertad es para el bien y la virtud la capacidad de elegir bien (la obra buena). El bien entonces es lo que la virtud elige libremente.

Para Kant, la razón pura en si misma, es la libertad. Lo que en definitiva determina la libertad kantiana es la ley moral. Se debe obrar de manera que el principio de una ley universal (moral) guie la propia voluntad. La érica de Aristóteles por su parte, es fundamentalmente una érica de virtud (disposición habitual y firme de hacer el bien). La felicidad es para él la virtud misma. La libertad de Kant es, a la vez, virtud y bien. La virtud en Aristóteles es, a la vez, libertad y bien. La fuente esencial y escondida de la ética es el "amor", porque ahi es donde reside el bien absoluto, desde donde por medio de la virtud reside la libertad y finalmente la esencia de la moral.

\section{Formulación de los principios morales}

G I razonamiento moral culmina con la formulación de - erincipios éricos. El juicio moral es el acto mental que afirma o niega el valor moral frente a una situación o comportamiento. Por medio del juicio moral se pretende la búsqueda de la verdad. El juicio moral se pronuncia sobre la presencia (o ausencia) de un valor ético, en una situación o comportamiento concreto. Los principios morales se entienden como direcciones del valor. Por ejemplo "ama a tu prójimo como a ti mismo", es decir, lo que quieras para ii, hazlo a los demás. Los principios éricos orientan y dirigen al sujero. Se visualizan, en una realidad concreta sus consecuencias, identificando la presencia de un valor. La norma establece el contenido del comportamiento (mientras que el principio dirige las accicudes). Las normas morales son necesarias para discernir lo que esta bien y lo que esta mal. Desde el punto de vista moral, se entiende por norma la obligación del valor moral. Toda persona necesita conocer los limites precisos de respetar. Para ello uriliza mediaciones (valores morales) que se apliquen al comportamiento concreto.

La Deontología, que postula a la validez de la norma independientemente de las consecuencias. Deja lugar para las excepciones o recurre a principios interpretativos que asumen la importancia de la circunstancias concretas para resolver problemas éticos conflictivos. (ejemplo de excepción: matar en legítima defensa, la guerra justa, la pena de muerte). La érica cristiana, que privilegia la atención al objeto moral y que defendiendo la postura deontológica, no rechaza considerar la teleologia interior del obrar en cuanto orienta a promover el verdadero bien de las personas, sino que reconoce que éste sólo se pretende realmente cuando se respetan los elementos esenciales de la naturaleza humana. La Teleologia, que se atiene a las consecuencias previsibles. Cae en el "consecuencialismo" si desconoce el discurso objetivo de la norma porque reduce a la ética a una apreciación subjetiva a partir de las solas circunstancias, negando la posibilidad de elaborar un discurso capaz de orientar al sujeto en las distintas situaciones.

También se hace la distinción entre la actitud moralmente buena o mala de la persona, y que depende la voluntad o falta de voluntad de tender hacia el bien; y del comportamiento moralmente recto o erróneo, que depende del juicio en virtud, del cual una acción debería o no cumplirse.

\section{Conciencia}

T a conciencia es el núcleo más secreto y sagrado del hombre, en el que está solo con Dios, cuya voz resuena en lo más intimo. Es aquella capacidad moral de la persona que le dice subjecivamente lo que es bueno y malo, y que le manifiesta su obligación moral. Es un juicio de la razón por el que la persona reconoce la calidad moral de un acto concreto. La conciencia bien formada es recra y veraz; formula sus juicios según la razón, conforme al bien. Frente a una decisión moral, la conciencia puede formar un juicio recto, conforme a razón y a la ley divina, o al contrario un juicio erróneo, que se aleja de ellas. El ser humano debe obedecer siempre el juicio cierto de su conciencia. Li conciencia moral puede formar juicios erróneos por ignorancia (no siempre exentos de responsabilidad). 


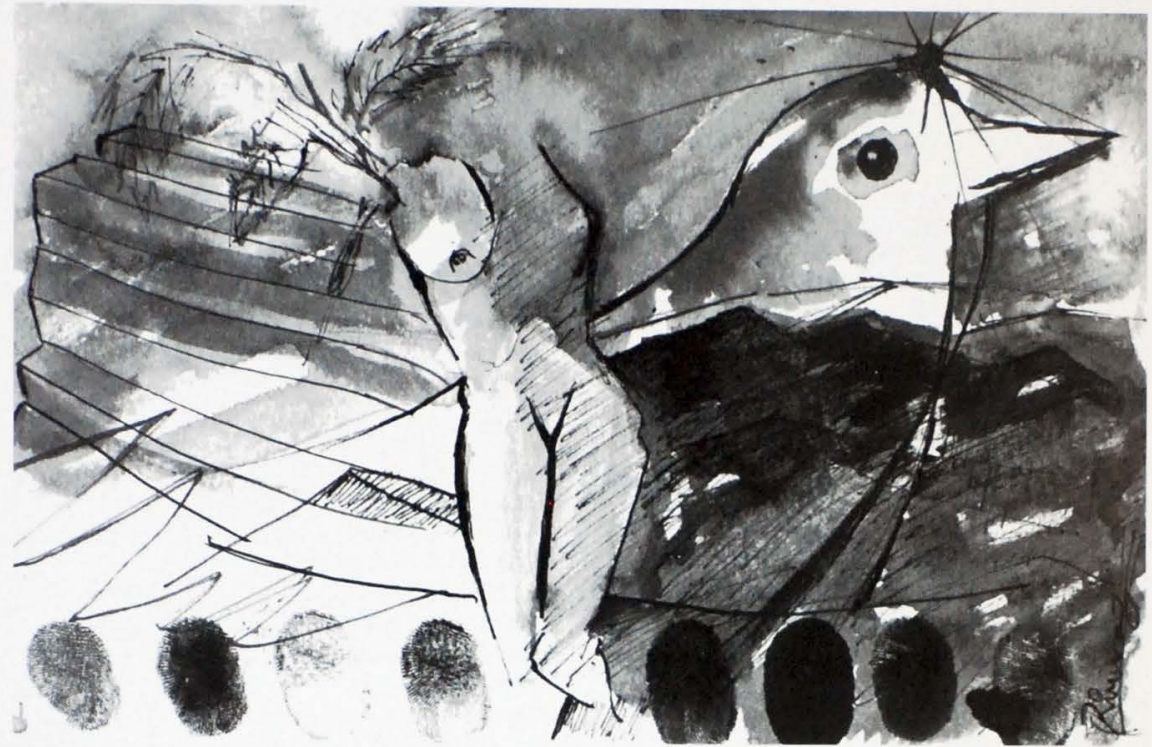

\section{El enfoque de la ley natural}

e acuerdo con este enfoque, existen siete valores
fundamentales que se identifican con la esencia del ser humano.

1. La vida respeto a todo lo que tiene vida. 2. La amistad amor al prójimo. 3. El conocimiento y derecho a la instrucción. 4. Belleza participación en lo que uno considera bello y alimenta el espiritu. 5. Alegria tener buen ánimo 6 . Religión participación activa de la espiritualidad y purificación del alma. 7. Racionalidad prácrica ejercicio de una vida consecuente en la busqueda de los valores fundamentales. Participar de estos valores fundamentales, hacen del hombre un ser más pleno, más humano. Atentar a los mismos significa ser menos humano, se actúa antiéticamente; se contradice la voluntad divina pretendida para cada ser.

Toda persona esta llamada al compromiso con estos valores fundamentales. De dicho compromiso se derivan cuatro principios (éricos) de justicia personal a seguir por todo hombre: a. No contrariedad No actuar directamente en contra de un valor fundamental. b. Libertad a mayor libertad mayor es el compromiso con los valores fundamentales. c. Reacción toma de medidas para evitar acciones contrarias a estos valores. d. Bien común contribuir al bien común facilitando la participación de los demás de los valores fundamentales.

\section{La trascendencia de los valores humanos}

D iógenes, filósofo griego originario de Sinope (Asia destacado de la escuela cínica fundada por Antistenes. Desterrado de su ciudad natal, vivió la mayor parte de su vida en Atenas. Contemporáneo de Aristóteles y de Alejandro Magno, su vida nos es conocida, sobre todo, por Diógenes Laercio y otros autores antiguos, que cuentan sucesos curiosos. En dichas narraciones, Diógenes se nos aparece siempre como un personaje extravagante que lleva hasta las últimas consecuencias la tesis básica de la escuela cínica: el vivir conforme a la naturaleza, el desprecio de las convenciones sociales y la absoluca independencia respecto de las instituciones.

La tradición ha recogido numerosas anécdotas sobre su vida. Sin apego ninguno por los bienes materiales, Diógenes vivía como un vagabundo, como un "auréntico perro" (de donde deriva el nombre de cinico), se aloja dentro de un tonel. Y' estaba una mañana sentado al sol, junto a su tonel, cuando 
acudió a visitarle Alejandro Magno, a cuyos oídos había llegado la fama del filósofo. Y' Alejandro, para mostrar su espléndida generosidad, le dijo: - Pideme lo que quieras y te lodaré. Alejandro se había situado entre el sol y Diógenes. Y éste le contestó: - Sólo te pido una cosa: que no me quites el sol.

En otra ocasión, iba por las calles, en medio de la multitud, con una rea encendida, a plena luz del día. Le preguntaron: -QQué buscas con esta luz a pleno dia? - Busco a un hombre. Queria decir con esto, que buscaba a un hombre verdadero, no a un miembro del rebaño embrutecido. Abundandosobrelo difícil que resultaba encontrar a un verdadero hombre entre sus vecinos, idea que, al parecer, no habia sido adecuadamente captada por sus coetáneos, gritó en orra ocasión: "Hombres a mí". Cuando se le acercaron unas cuantas personas a socorrerle, comenzó a escupirlas diciendo: "He dicho hombres, no basura".

\begin{tabular}{c}
\hline La vida es moralmente \\
virtuosa si se tiene el hábito \\
de la virtud, "por el cual el \\
hombre se hace bueno y por el \\
cual ejecuta bien su función \\
propia"; la práctica habitual \\
de las virtudes éticas, que \\
consisten en un justo medio \\
entre dos excesos, hace al \\
hombre moral y lo dispone a la \\
felicidad.
\end{tabular}

Las fuentes de la doctrina sobre la virtud son Platón, Aristóteles y Tomas de Aquino, fiel comentador en este punto de las teorías aristotélicas. La virtud es, en Platón, el dominio de la parte racional del alma sobre la parte apetitiva (tendencia a lograr un fin sensible) y sobre la parte irascible (tendencia a evitar un daño sensible). Aristóteles desarrolla este esquema y sistematiza la doctrina de la virtud en el Libro II d e la Ética a Nicómaco. El alma racional platónica es en Aristóteles la diánoia o razón discursiva en su función práctica (excluidas las funciones teóricas y productivas de la razón); el buen funcionamiento de esta razón supone la virtud dianoérica de la prudencia, o phrónesis, la racionalidad práctica, y a ella incumbe el saber llevar una vida moralmente virtuosa.

La vida es moralmente virtuosa si se tiene el hábito de la virtud. "por el cual el hombre se hace bueno y por el cual ejecuta bien su función propia”; la prácrica habitual de las virtudes éticas,

A pesar de las excentricidades de este filósofo cínico, hay un punto de razón en sus palabras: hoy, como ayer, estamos más preocupados por la imagen, por las apariencias, que por el modo de ser y por la verdad sobre nosorros mismos. No son pocos los sociólogos y filósofos que subrayan la falta de valores de la sociedad actual. Cuando los miembros de una sociedad se desvalorizan individualmente, tarde o temprano esto se refleja en la colecrividad. Como son esos valores precisamente los que nos hacen humanos, perderlos supone la deshumanización personal y social de la civilización presente. Esto puede explicar por qué en la actualidad existen tantas apelaciones a los valores humanos y por qué éstos brillan tanto por su ausencia.

\section{Las virtudes humanas}

E ntre esos valores humanos, ocupan un puesto preponderante las virtudes humanas. La palabra virtud, del latín virtus, igual que su equivalente griego, areté, significa "cualidad excelente", "disposición habitual a obrar bien en sentido moral". Puesto que se trata de una disposición o capacidad adquirida, por el ejercicio y el aprendizaje, de hacer lo que es moralmente bueno, la virtud es una cualidad de la voluntad que supone un bien para uno mismo o para los demás. Y en esto se distingue una virtud de cualquier orra disposición habitual, como por ejemplo la salud, la fuerza física o la inteligencia: en que "en un hombre virtuoso la voluntad es la que es buena". que consisten en un justo medio entre dos excesos, hace al hombre moral y lo dispone a la felicidad. Por esto la ética no es sino el cumplimiento del fin del hombre. En esta misma línea, Tomás de Aquino distingue entre apetito natural, el de la comida, por ejemplo, sensitivo e impulsado por la imaginación o la sensación, y el racional, que es la determinación de la voluntad.

El concepto aristorélico de virtud, fundamento de la ética, pasa con el Aquinate al mundo cristiano. A las virtudes morales de Aristóteles y a las principales o cardinales -así llamadas por San Ambrosio que Platón menciona como fundamentales en La República a saber: sophía, prudencia; andreia, fortaleza; sophrosine, remplanza; y dikaiosyne, justicia, añade las virtudes teologales (fe, esperanza y caridad), que tienen por objeto a Dios.

\section{Los hábitos}

a clave del crecimiento interior del hombre se basa en Luna peculiaridad de su espíritu: todos los actos volunt arios dejan huella: el hombre aprende a obrar a medida que obra. Esto se aprecia muy claramente en la capacidad de adquirir récnicas. Todos conocemos hombres muy hábiles, no sólo malabaristas, sino también carpinteros, artesanos, deportistas, músicos. Todos tienen en común que son capaces de realizar fácilmente y con perfección acciones que para nosotros serían imposibles o, por lo menos, muy difíciles. Y 

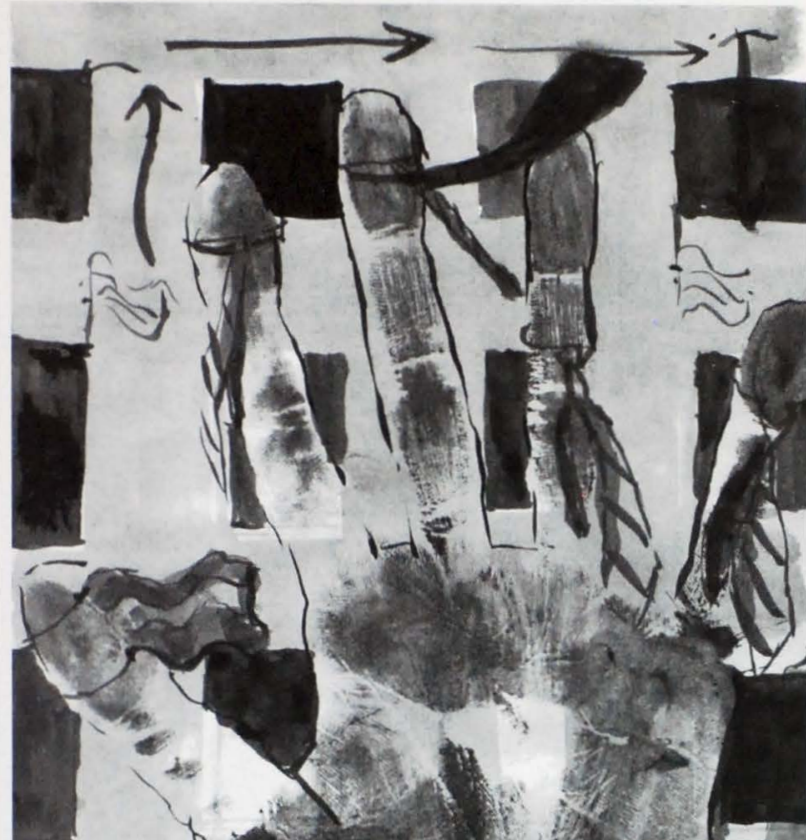
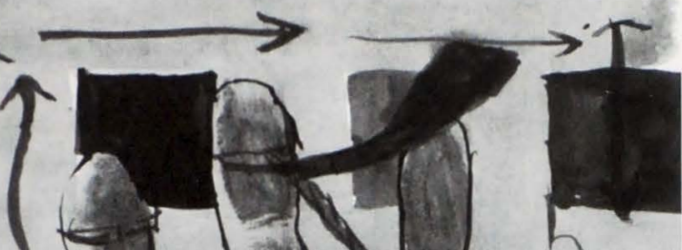

.

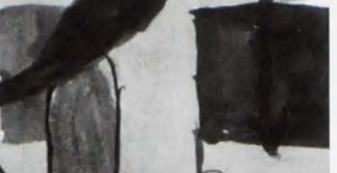

strucción ética del hombre des

sde una perspectiva filosófica acros en la misma dirección.

ent'. 8 entó

rodos han llegado a dominar esas técnicas (de poner un tirafondo, saltarcon pértiga, tocar el arpa.) del mismo modo: repitiendo muchas veces las mismas acciones. En ocasiones -como un buen intérprete de cualquier instrumento-, ensayando muchas horas al día y muchos dias al año.

Tanto el bien como el mal obrar forman costumbres e inclinaciones en el espíritu; es decir, hábitos de obrar. A los buenos se les llama "virtudes"; y a los malos, "vicios". Un hábiro bueno del espíritu es, por ejemplo, saber decidir sin precipitación y considcrando bien las circunstancias. Un vicio, en cambio, en el mismo campo, es el atolondramiento, que lleva a decidir sin pensar $y$ a modificar muchas veces $y$ sin morivo las decisiones tomadas. Algo tan importante como lo que llamamos "fuerza de voluntad" no es orra cosa que un conjunto de hábitos buenos conseguidos después de haber reperido muchos

Ésta es la regla de oro de la educación del espíritu: la repetición. Hay un pequeño caso que afecta a una parte importante de la humanidad y que nos of rece un buen ejemplo: la hora de levantarse de la cama. Casi todos los hombres tenemos la experiencia de lo que supone en ese momento dejarse llevar por la pereza, $y$ los que son más jóvenes la tienen de una manera más viva.

Si, al sonar el despertador, uno se levanta, va creando la costumbre de levantarse, $y$, salvo que suceda algo como un cansancio anor-mal, resulta cada vez más fácil hacerlo. En cambio, si un día se espera unos minutos antes de dejar la cama, al día siguiente costará más esfuerzo; y si se cede, todavia más al día siguiente. Así hasta llegar a no oír el despertador.

\section{Virtudes humanas fundamentales}

T as virtudes humanas funda- mentales son, desde Aristóteles, las siguientes: prudencia, justicia, fortaleza y templanza. La prudencia es la virtud que dispone la razón práctica a discernir en toda circunstancia nuestro verdadero bien y a elegir los medios rectos para realizarlo. "El hombre cauro medita sus pasos" (Prov. 14,15).

La prudencia es la "regla recta de la acción", escribe Santo. Tomás (Suma teológica. 2-2, 47,2), siguiendo a Aristóteles. No se conf unde ni con la timidez o el temor, ni con la doblez o la simulación. Es Ilamada la "auriga virtutum": Conduce las otras virtudes indicíndoles regla y medida. Es la prudencia quien guia directamente el juicio de conciencia.

El hombre prudente decide y ordena su conducta según este 
juicio. Gracias a esta virtud aplicamos sin error los principios morales a los casos particulares y superamos las dudas sobre el bien que debemos hacer y el mal que debemos evitar.

La justicia es la virtud moral que consiste en la constante y firme voluntad de dar a cada uno lo que les es debido. l.a justicia para con Dios es llamada "la virtud de la religión". Para con los hombres, la justicia dispone a respetar los derechos de cada uno y a establecer en las relaciones humanas la armonia que promueve la equidad respecto a las personas $y$ al bien común.

La fortaleza es la virtud moral que asegura en las dificultades la firmeza y la constancia en la búsqueda del bien. Reafirma la resolución de resistir a las debilidades y de superar los obstáculos en la vida moral. La virtud de la fortaleza hace capaz de vencer el temor, incluso la muerte, y de hacer frente a las pruebas $y$ a las persecuciones. Capacita para ir hasta la renuncia y el sacrificio de la propia vida por defender una causa justa.

La templanza es la virtud moral que modera la atracción de los placeres y procura el equilibrio en el uso de los bienes creados. Asegura el dominio de la voluntad sobre los instincos y mantiene los deseos en los límites de la honesridad. La persona moderada orienta hacia el bien sus apetitos sensibles, guarda una sana discreción y no se deja arrastrar para seguir la pasión de su corazón.

Los hábitos buenos -las virtudes- consiguen que se vaya estableciendo el predominio de la inteligencia en la vida del espíritu. Los vicios dispersan las fuerzas del hombre, mientras que las virtudes las concentran y las ponen al servicio del espíritu.

La persona que es perezosa, que tiene el vicio de la pereza, puede fijarse, quizá, propósitos estupendos, pero es incapaz de cumplirlos: su espíritu resulta derrotado por la pereza, por la resistencia del cuerpo a moverse.

Todo estudiante experimenta intimamente esta lucha entre lo que se propone estudiar y lo que después realmente estudia. Sorprendentemente, no basta con proponerse una cosa para ser capaz de vivirla: ¡qué difícil es dejar de fumar o guardar un régimen de adelgazamiento! No basta una primera decisión.

\section{Dominio de si}

Cólo con esfuerzo -repitiendo muchas veces actos que $\checkmark$ cuestan un poco-se consigue el dominio necesario sobre uno mismo. La persona que tiene virtudes es capaz, por ejemplo, de no comer algo que no le conviene, aunque le apetezca mucho, o de trabajar cuando está cansado, o de no enfadarse por una minucia; logra que, en su actuación, predomine la racionalidad: es capaz de guiarse -al menos hasta cierto punto- por lo que ve que debe hacer.

Quien no tiene virtudes, en cambio, es incapaz - también hasta cierto punto- de hacer lo que quiere. Decide, pero no cumple: no consigue llevar a cabo lo que se propone: no llega a trabajar lo previsto o a ejecurar lo decidido.

Asi resulta que la persona que tiene virtudes es mucho más libre que la que no las tiene. Es capaz de hacer lo que quiere -lo que decide-, mientras que la orra es incapaz. Quien no riene virtudes no decide por si mismo, sino que algo decide por él: quizá hace "lo que le viene en gana". Pero "la gana" no es lo mismo que la libertad.

La gana es una veleta que necesariamente se orienta hacia donde sopla el viento. El perezoso puede tener la impresión de que no realiza su trabajo porque "no le apetece" o "no le da la gana" y hacer de esto un gesto de libertad, pero en realidad es una esclavitud. Si no trabaja en esemomento, no es por ejercitar su libertad, sino precisamente porque "no es capaz" de trabajar. Y la prueba de esto es que "las ganas" se orientan con una sorprendente constancia siempre en el mismo sentido.

A la persona que se ha acostumbrado a comer demasiado, "sus ganas" le inclinan una y otra vez, un dia tras otro, a comer más de lo debido, pero raramente a guardar un día de ayuno. $\mathrm{Y}$ al que es perezoso, le llevan a abandonar un día tras orro su trabajo, pero raramente a realizar un sacrificio extraordinario.

Las virtudes van extendiendo el orden de la razón y el dominio de la voluntad a todo el ámbito del obrar. Concentran las fuerzas del hombre, que se hace capaz de orientar su actividad en las direcciones que él mismo se propone. La misma palabra "virtud" que es latina, está relacionada con la palabra "hombre" (vir) y con la palabra "fuerza" (vis).

Lagranfuerza de un hombre son sus virtudes, aunque quizá su constitución física sea débil. Sólo quien tiene virtudes puede guiar su vida de acuerdo con sus principios, sin estar cediendo, a cada instante, ante la más pequeña dificultad o ante las solicitaciones contrarias.

En cambio, los pequeños vicios de la conducta debilitan el carácter y hacen a un hombre incapaz de vivir de acuerdo con sus ideales. Son pequeñas esclavitudes que acaban produciendo una personalidad mediocre. Y es que, como decía Aristóteles, "nuestro carácter es resultado de nuestra conducta." 